\title{
Discussion on the Essence of School Physical Education
}

\author{
Xiaojun Li \\ Yichun University, Yichun, Jiangxi, China
}

\begin{abstract}
This study from the essence of school physical education do the cultural interpretation, in order to display relationships of sports, human and culture, and put forward with cultural connotation, making sports as a kind of human's practice. From the perspective of culture, the essence of school physical education has opened a door for the study of school sports essence, combined with human nature and human needs, play of human subjectivity and promote people's all-round development, to better grasp the development direction of modern physical education in school.
\end{abstract}

Keywords-School physical education, nature, humanism.

\section{I.THE ESSENCE OF PHYSICAL EDUCATION}

The essence of sports is what sports is, the essence of sports is the essential characteristic of sports(namely difference). The school sports is one of the basic content of the sports, which is an important part of school education. It laid the physical health, edify sentiment, improvement of the mind and the character as the starting point and the foothold for all the educated, to master the scientific methods of exercises, physical fitness, then benefit the whole life. Study on the essence of school physical education is not only a basic but a difficult issue of school sports. The school sports is an important part of human culture education, which makes use of all kinds of natural factors and human conditions. It connects with human measures and body exercise to improve health, enhance physical fitness, which is a form of culture.

\section{II.THE ESSENCE OF SCHOOL PHYSICAL EDUCATION}

This has been the universal focus problem. China's cultural circles and educational circles had set off a heat discussion about the school sports, directly and sharply pointed out many problems, and put forward many constructive suggestions. The voice of the highest cultural implication of interpretation of school physical education is from the humanistic position, which put forward that school physical education is an important part of human culture, the unity of instrumentalism and humanism. which is the basic characteristics of physical education curriculum.

\section{A. To locate the nature of sports disciplines from the} instrumental and humanistic standpoint

From the unity of instrumental and humanism perspective to locate the nature of sports disciplines, it provides a new perspective for school physical education practice. However, for a long time, it has some conflict between the school physical education and the spirit of new curriculum standard in reality. The most prominent problem is the limitation in the standard school physical education, the function of school sports limited in knowledge and the grasp of technical skills and the analytical framework of sports ability. With this kind of education idea, the value choices of school sports pay more attention to the practicality. Sports learning are viewed as skilled tasks, and extremely neglected human cultivation and construction function. The pure instrumental view is the fundamental cause of the loss of school sports culture. But the good news is that the school sports field has begun to examine the disadvantages of school sports pure instrumental, turn to seek a breakthrough and innovation from sports discipline tools of the humanities and the integration, which is really transfer from the education standard concept to the development of people and the integrity of their construction. So to speak, discovering the cultural traits in sports discipline, grasping the binary one and promoting the overall development of individual student life have become the basic guiding ideology of school physical education reform. Have a clear understanding of the nature of school physical education and establishding the school sports culture essence will be beneficial to reform the malpractice, transform the school physical education idea, carry forward the spirit of humanism, promote the school sports man's mission and speed up the school sports curriculum and education reform, so this research has certain theory value and the practice significance.

\section{B. To understand the physical problems in what essence view}

Study on school sports whether from past or future judgment, we should identify what the essence of school physical education is and why understand physical problems in such a nature way. It provides theoretical sources, research on school physical education development direction and organization management and restricts the other links and ways of school physical education. At all times and in all countries, many thinkers, educators and gymnasts on Sports profoundly reveal the essence of school sports, which is our theoretical analysis of school sports essence. From the middle 1980s the discussion on the problems of the sports essence and sports terms, to the people-oriented and health first raised the century sports world discussion on the essence and connotation of sports never stop. It has a very important significance for us to think about this question, which will make us further 
understand and grasp the objective of school physical education and establish training cross century objective of talents of education.

\section{Many scholars at all times and in all countries make many analysis and research about the school sports essence from different angles}

They made a deep explanation on the nature of school sports from different views, which have a profound significance for understanding school sports essence, and it is also an important basis for our study of school physical education in nature; these studies have important reference value to the research. Study on the essence of sports is a complex subject of sports theory research, the definition of sports essence has about 10 species from the literature, Public opinions are divergent and unable to agree on which is right, although the nature of sports opinions are different. It has its specific reasons and inevitably biased from the evolution history of the essence of school physical education.

\section{From the point of view of Education}

From the perspective of establishment and development of school sports, school sports have always been an important part of school education. In the early period of slave system, the educational system of the ancient Greek has viewed sports as an important part of education. Whether the Spartan educational system makes the sports activities as the main content of education, or regardless of Athenian education system emphasizes the coordination of the body and fitness, action of vigorous and flexible degree as the aesthetic standard and judge the people to receive education, ancient Greek education theory contains rich thoughts of physical education, in designing educational systems of Plato, his integrity and spirit of sports was viewed as a way to moral perfection; while the Japanese scholar Shantou Abe thought that sports is a physical activity as a media, meanwhile it's an education to cultivate good health and social character. In modern China, Kang Youwei, Liang Qichao, Yan $\mathrm{Fu}$, who were the representatives of the reformists systematically accepted and introduced the modern western education and physical education. Kang Youwei listed sports as the content of education at all levels in five Datong book, and emphasized the status and function of sports in school education. At the same time, our country famous gymnasts Wu Yunrui, Yuan Dunli and Fang Wan Bang thought that sports is a large muscle activity and adaptaction to the environment of the body as a tool to achieve an education purpose. They insistend on physical education. After the foundaction of new China, we gradually reformed sports curriculum to a formal discipline with a scientific content, and established the school physical education's purpose, meaning, contents and methods. The famous scholar Yang Wenxuan, Li Guiling and Zhou Arguing suggestend that sports is a body movement as the basic means to enhance physical fitness and improve education process in the body.

\section{E. From the physical body theory}

That school sports should belong to the category of pedagogy in the field of social sciences, emphasized that it should follow the principle of people-oriented and havet new ideas and innovative spirits. Based on defining the essence and nature of the difference, we pointed out that physical education is the essence of sports. From the view of building up health, in the thousands of years of cultural history of education in our country, the Western Zhou Dynasty's education emphasized Wenwu combination. Zhou Li Stuart officer Paul's said: Paul's Zhang Jean Wang is evil; but he raised a child of the road, taught the six arts. The six refers to ritual, music, and archery, royal, book, and digital, so as to establish the contents of ancient schooling. In this time of advanced education system, archery and royal are military training, with sports nature, and also a means to improve their health. At the Western Renaissance, humanists proposed physical and mental ideal that emphasized the individuality and personality and viewed cultivateding the body strong and independent spirit as an important task of sports. Great educator in modern China Mr. CAI Yuanpei pointed out that the original meaning is to enhance the physical fitness of students, promote students' physical health as the main objective. Mao Zedong insistend that sports person, who is human strengthen their body, make their body develop well as averaged rules of order. Contemporary scholars Lin Xiaofeng, Teng Chi king and Ran Bing more directly put forward: sports is the education of enhanceding physical fitness, real sports must strengthen the Constitution for the industry; and through the historical review of researches on sports essence. He also pointend out that the essence of sport is to enhance physical fitness, promote the development of physical and mental health, physical fitness is the foothold and starting point of physical education.

\section{F. $\quad$ From the perspective of culture}

From the view of the domestic research situation, the study on exploreding the nature of school sports culture is laciness. But some scholars put forward an idea that culture and sports are relatively closed to the humanistic sports concept, such as Feng Xia, Hu Xiaoming, they thought that humanistic sports view is a human-scale, taking human development as the ultimate goal of a series of sports thoughts and ideas. It is formed from one's own point of view on sports awareness, it stressed the principal position in the sports practice, emphasisding people's potential and creativity; stressed that physical education is an important way of promoteding the people's all-round development. In contemporary, it reflected on the overall pursuit of modernization; Hhumanistic sports concept refers to the awareness of sports pourend into the people-oriented spirit. Humanistic sports concept provides a new perspective to the 
study of school sports essence, and also provides reference for this study. The famous scholar Ji Liu thought sports is the national cultureal interests. There are many scholars such as Bai Jinxiang, Yi Jiandong and others discussed the cultural essence of sports from the perspective of culture, they thought that culture is a social phenomenon, a historical phenomenon, characterized by very complex feature. Sports is a product of human body movement and a practical activity that human beings pursuit harmonious development of body and mind. It is a kind of social practical activity for people to exercise as a pursuit of form and means of physical and mental development under selfconsciousness, the basic cultural meanings in physical activity is the pursuit of comprehensive and harmonious development of people body and mind. Sports has both common features of human culture, such as the nationality and humanity, time and eternity; It also has the identity of subject and object, physical charactersticks and hermitage, the createone of temporal and spatail scalability,which is easier to understand the affinities and other special cultural characteristics.

\section{III.THE VALUE AND SIGNIFICANCE OF THE SCHOOL SPORTS}

What is the essence of school physical education? Where does the value and significance of the school sports exist? This has the being asked question since the school sports went into school. Taiwan scholars $\mathrm{Xu}$ Yixiong and $\mathrm{Xu}$ Yuanmin pointed out: if the sports concept is not correct, it is the most important barrier to the promotion of physical education. In the long process of human history, in the process of constant evolution and development of school sports into the school, due to the limitations of their awareness of school sports and for some utilitarian purpose, school physical education's operation modes has often been distorted, leading to alienation, to the function of physical education in school instead of the essence of school physical education. This study from the hhistorical evolution of the concept of school physical education observed the essence of longitudinal study history school sporats ontology evolution, and ancient and modern scholars summarized into three kinds of conceptions of nature according to research on the essence of school physical education.

\section{A. Enlightenment ontology}

The essence of ancient school sports is the most typical; it refers to school sports established on the basis of moral education, ideological and political education, but it makes the cultivation as foothold. In this kind of valuable orientation of subsection, people's all the fact judgement activities have been incorporated into the ethics mode, and school sports has become ritualized and socialization of the Confucian tradition of etiquette.

\section{B. Tools for Ontology}

It is a breakthrough of the former, highlighting the characteristics of school sport itself, but the pure instrumental tendency ignored the factors of sports itself containing a person. The tool upsides down physical relationship between physical purpose and means, making sports go to the opposite trend of life.

\section{The cultural outlook of noumenon}

It seeks to correct the biasas of tool body, and the extension of the ontology is broader than enlightenment, breakding the closed political and ideological education, making the school sports located into the human and making people's overall training and personality development as the fundamental fulcrum, which is the high degree integration of education ontology and the tool body.

\section{CONCLUSION}

The so-called school culture essence referred to the school sports is not only a tool of knowledge, the carrier of culture, but also a kind of cultural form, an important part of human culture. The unity of instrumentalism and humanism is the basic characteristic of school physical education curriculum. The essence of school physical education should be a process of culture, which is not only a process of cultural transmission, but also the culture of the formation process, more importantlee, it is a process to nurture the human nature and promote life growth. School sports cultureal eessence suggests that physical education and humanistic education should be unified, and adviceate students' sports ability, at the same time, to be true to make the subject of culture of people as the object, aiming at students' integrity construction, prootding the overall generation of individuall. For a long time, the school's most prominent problem is limited in the standard of physical education; it only does emphasize the pure tool of school physical education. The school sports teaching emphasize practicability in the value selection, while people viewed learning as a skill task, and extremely contempt for human's cultivation, construction function. Thus, understanding the nature of school sports and setting up school sports culturalal essence will be beneficial to reform the malpractice, carry forward the spirit of humanism, promote the school sports man's mission, speed up the sports curriculum and education reform action. The study will discuss the school physical education culturalal essence from all-round and multiplea angle. Then put forward the characteristics of physical education culturalal essence based on above: Firstly, the overall sense of understanding. School physical education has the feature of entirety; school sports should improve students' overall understanding ability of the school sports appreciation. Secondly, body experience. The school sports teaching process is a special experience. According to the teaching characteristics and rules, teaching can stimulate students' interest in learning, cultivate the habit of physical exercise and the ability to meet demand of students' participation in sports, so that make students' experience in the movement have a variety of stimulus, at the same time, the same feeling contains rich 
humanistic spirit. Thirdly, spiritual formation. The fundamental spirit of school physical education is a kind of spiritual education, which is a kind of humanization education. People's education is also the spiritual growth of education learners. Forthly, the game pleasure. Sports is an activity of the game, without entertainment, sports is not the sports, and the charm of sports lies in the rich in strong entertainment. It is the most important reason why the masses of young student love sports. Fifthly, integration and unity. The school sports culturalal essence breaks the rigid thinking mode of the binary opposition, overcomes onesided aspect, advocates the organic unity of instrumental and humanism, the comprehension of tool training and humanistic education, the integration of science thought and humanistic thought.

\section{REFERENCES}

[1] TANG, J. Confirmation of Sport Essence in Accordance with Modern Society Development. JOURNAL OF BEIJING UNIVERSITY OF PHYSICAL EDVCATION, 22(4):16-19, 1999.

[2] LI, G.L, Further understanding of the essence of Physical Education. JOURNAL OF PHYSICAL EDUCATION, (3):87-89., 2000.

[3] JI, L, Sports is the national culture interest. The Journal of Sport History and Culture, (10):70. 2003.

[4] ZHAO, L.J. Humanities thinking on the essence of Physical Education. Journal of Shanghai Physical Education Institute, 27(5):20-21, 2003,

[5] LI, G.L, Essence of School Physical Education. JOurnal of Shenyang Institute of Physical Education, 23(4):532-533, 2004. 